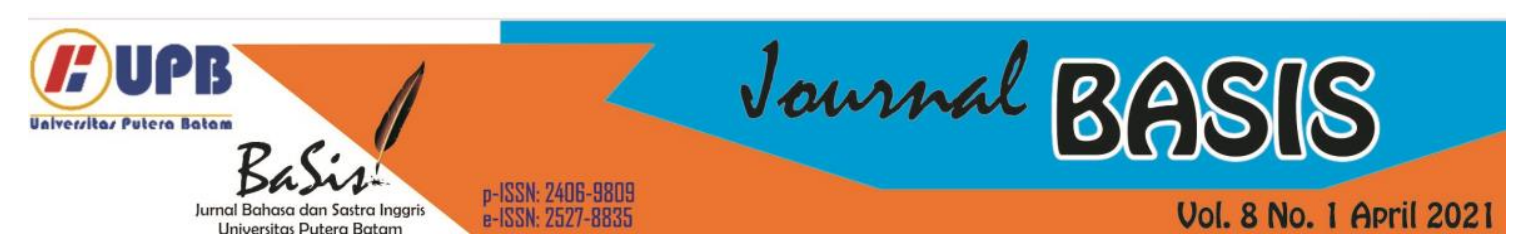

\title{
THE LANGUAGE OF INFORMALITY WITHIN ELT CONTEXT
}

\author{
Jumanto Jumanto \\ Universitas Dian Nuswantoro, Semarang, Jawa Tengah, Indonesia \\ ilhamj@dsn.dinus.ac.id \\ Emik Rahayu \\ Universitas Dian Nuswantoro, Semarang, Jawa Tengah, Indonesia \\ emik.rahayu@dsn.dinus.ac.id
}

\begin{abstract}
This research paper explored aspects of informality in the English language, the target hearers referred to by the aspects, and the functions the aspects convey in verbal interactions or communication, and its contribution to English Language Teaching (ELT) in the world. The research data are retrieved, obtained, and verified from informal-English-affiliated URLs or Websites, i.e. Web-Data as sources of informal English. As the findings, informal English involves the notorious, casual, heteregeneous, inconsistent, irregular, unorganized, incomplete, shorter, cut-down, reversed-up, and speaker-dependent aspects, and has the direct and literal nature. Informal English with its relatively any topics, personal and private, is used for close people to confirm their in-group solidarity or membership of a social group within relaxed situations and unofficial contexts. Knowledge and practices of informal English are necessary for teachers as well as learners. ELT teachers should include informal English in their teaching-syllabus material with particularly-set circumstances. Learning the knowledge and practices of informal English through ELT classrooms should prevent English learners from uncontrolled learning exposures to various informal morally-dangerous settings. This way will expectedly encourage English learners to be alert and careful in using informal English, hence encouraging them to maintain interpersonal and social harmony to some broader extent.
\end{abstract}

Keywords: politeness and camaraderie, verbal interactions, solidarity, informal English

\section{INTRODUCTION}

Language use is a matter of probabilities, either verbal language or non-verbal language (Jumanto, Rizal, and Nugroho, 2017: 111). Politeness, impoliteness, rude situations, awkward situations, formality, informality and other aspects that may incur and affect language use towards interpersonal as well as social harmony are worth considering. Formality happens in our speech society in our daily context, so does informality. Formality in language use happens when we are in contact with superiors, not close people, and sometimes with those we meet for the first time. We have been very much told in family and taught in classroom about

this formality in language use, as it is what we commonly believe to be good, decent, and appropriate when speaking a particular language to our interlocutor or to our audience, or when writing that particular language to our readers. Formal grammar in our utterances or grammatically correct sentences in our verbal communication are believed to be polite. This is what we have believed so far. This is what has been indeed true so far. Formality and politeness are regarded as equivalent (Sifianou, 2013: 88).

Harmony is not something we automatically deserve, but it is something we interpersonally or commonly earn. 
Harmony, interpersonal or social, can be achieved by language use. In this context, education is one way to be considered for maintaining a national harmony (Jumanto, 2017), and one way of educating languages is by teaching them in the classroom. This also applies in the English Language Teaching (ELT) context.

Practices and theories of ELT we have experienced as well as done so far are directed to communicating attitudes, ideas, and ideologies to others in a relatively good verbal and non-verbal manners, which pragmatically is inevitably considering and maintaining the face of a particular hearer or a hearer's group. This face concept of politeness (Goffman, 1959; Brown and Levinson, 1987) which leads to interpersonal face as well as social face is important and favorably applied in interactions or communication between a speaker and a hearer, as interpersonal harmony and social harmony are usually at stake. Harmony is a possibly promising outcome in ELT, to be taught to students as a goal set together in the teaching and learning of English language use.

As has been mentioned above that formality and politeness are equivalent (Sifianou, 2013), and that politeness and harmony are commonly believed as an interface interplay, we need also look at the reverse aspect of politeness, i.e. informality. Informality is practiced within interactions or communication among friends or close people or close communities, i.e. those usually having known each other or one another for a relatively long time. Informality is a favorable aspect or passion within the context of this circle, and thus probably important to be involved in ELT. When formality matters in interactions or communication between not close people, so probably does informality in interactions or communications between close people, as harmony is the same reward to be commonly fought for. The problem to be solved here is what aspects of informality for harmony should be taught in ELT. In the efforts for this, we need to stand on theories of positive face (Goffman, 1959), positive politeness strategies (Brown and Levinson, 1987), solidarity politeness (Renkema, 1993), and camaraderie (Jumanto, 2014). This stance is not alone. As in interactions or communication we are not talking to a cold wall, or even to a beautiful statue, or are not speaking alone (soliloquy), we also need to consider with whom we are interacting or communicating, and how close we are to a particular hearer. Here then we come to the aspects of power and solidarity in the part of hearer (Brown and Gilman, 1968). This research paper is trying to explore the language of informality, i.e. what aspects of informal English to be considered, whom the aspects are for and what functions they convey in verbal interactions or communication, and what probable contributions the aspects give in the ELT context.

\section{LITERATURE REVIEW}

This section consists of discussions of issues on informality and the proposed premises. The issues on informality are taken from Bangasser (2000), Sindzingre (2006), Kanbur (2009), and Heintz (2012). Informality is then brought into an interplay with language use for camaraderie with close people, i.e. informality, camaraderie, and close people. This part of section highlights theories taken from Goffman (1959), Brown and Gilman (1968), Brown and Levinson (1987), Renkema (1993), and Jumanto (2014a). The proposed premises based on previous researches are then presented and discussed before the verifying processes on the data obtained. 


\subsection{Issues on Informality}

Defining informality in linguistics is not very easy. After some exploration on some other disciplines, we have finally come to the economy context. The term informal was coined by Keith Hart in his article on informal income opportunities in Ghana, and the 1972 ILO report on employment and poverty in Kenya was the starting point of the subsequent notoriety of the 'informal sector' (Bangasser, 2000). The concept of informality then refers to heterogeneity and inconsistencies, which coins the terms of non-observed, irregular, unofficial, second, hidden, shadow, parallel, subterranean, informal, cash economy, black market, unmeasured, unrecorded, untaxed, non-structured, petty production, and unorganized (Sindzingre, 2006: 5-2$3)$. In accordance with this, Kanbur (2009: 1) asserts that informality is a term with dubious distinction of combining maximum policy importance and political salience with minimal conceptual clarity and coherence in the analytical literature. Kanbur, furthermore, adds that the informality literature is vast and its multifaceted nature was present at the creation (2009: 1). Heintz contends that informality features prominently in development discourse, accompanied with a vast and growing literature; and in tandem with this, there are growing inconsistencies in the way it is conceptualized and measured (2012: 3). Heintz proceeds that there is no single approach to defining informality and the definitions used in theoretical and empirical research often lack consistency from one study to the next (GuhaKhasnobis, Kanbur, and Ostrom, 2006; in Heintz, 2012: 5). From the assertions above, points of informality are summed up as follows:

(1) Informality is usually regarded as notorious, heteregeneous, and inconsistent;

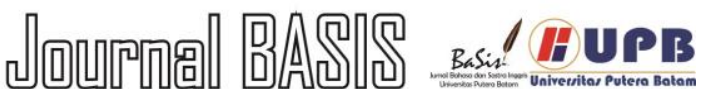

(2) Informality is non-observed, irregular, unofficial, second (to formality), hidden, shadow, parallel, subterranean, black-marketed, unmeasured, unrecorded, nonstructured, pettily-produced, and unorganized;

(3) Informality is dubiously distinctive and minimally conceptually clear and coherent;

(4) Informality is vast, multifaceted, and present at the creation;

(5) Informality has no single approach to its consistent definition.

In line with the summed-up points of informality above, and under elaborated linguistic viewpoints, Jumanto (2014a) provides a clear distinction between formal utterances and informal utterances. Formal utterances tend to have more complete, longer forms, and are in a good order; whereas, informal utterances have incomplete, shorter forms, and are not in a good order, and sometimes cut-down, reversed-up, and changed in favor of the speaker (2014a: II-339).

\subsection{Informality, Camaraderie, and Close People}

In line with the accounts above, in this section we are talking about the relationship among informality, camaraderie, and close people. In the context of this research, informality is directed to informal utterances, camaraderie refers to one aspect of politeness, and close people refers to one aspect of power and solidarity.

Informality in language use, thus informal utterances or expressions, based on and ajusted to the accounts by Bangasser (2000), Sindzingre (2006), Kanbur (2009), Heintz (2012), and Jumanto (2014a) above is, therefore, sharing the characteristics of being notorious, heteregeneous, inconsistent, irregular, unorganized, incomplete, shorter, cut-down, reversed-up, and changed in favor of the speaker. Thus, in 
line with utterances or sentences, informal utterances or sentences are then notorious, heteregeneous, inconsistent, irregular, unorganized, incomplete, shorter, cutdown, reversed-up, and speakerdependent.

Camaraderie or friendship as one aspect or one side of politeness. Jumanto (2014a) argues that the politeness theories in verbal interactions fall into or lead to two major poles, i.e. distancing politeness and closeness politeness. Distancing politeness refers to Goffman's negative face (1959), Brown and Levinson's negative politeness strategies (1987), Renkema's respect politeness (1993), and Jumanto's politeness (2014a). Closeness politeness refers to Goffman's positive face (1959), Brown and Levinson's positive politeness strategies (1987), Renkema's solidarity politeness (1993), and Jumanto's friendship or camaraderie (2014a). Furthermore, Jumanto asserts that closeness politeness is realized in close language with its informal, direct, and literal utterances which usually involves contractions, slangs, reverse-ups, changes, taboos, swearings, f-words, and uses any topics, personal and private (2014a: II-337). The speaker tends to use close language to close people for closeness politeness or camaraderie.

Close people are those close to us, those usually having known us very well and for a relatively long time. The word close here refers more to solidarity than to power in the theory of power and solidarity (Brown and Gilman, 1968). Thus, close people are those sharing solidarity together, as they have known each other or one another very well and for a long time. Examples of close people are those belonging to close communities. Close communities are probably the learner's close relatives, or other communities the learner is frequently involved in a social gathering with their parents or siblings (Jumanto, 2017: 217).

\section{RESEARCH METHOD}

3.1. Nature of the Research

This qualitative research is explorative in nature. An explorative research requires different kinds of activities and ways of thinking, creates a firm foundation for advancing knowledge, facilitates theory development, closes areas where most researches exist, and uncovers new research areas (Baker, 2000; Webster \& Watson, 2002). In this research, new ideas from others' works are extracted by synthesizing and summarizing them, so new theories and directions for future research can be built and suggested based on the evidence (Bolderston, 2008). The exploration in this research is done through interpretive techniques, and, therefore, interpreting is the main way of thinking. Before the interpreting process, premises for knowledge advancement and theory development are set upon reviewing established theories of informality or closeness politeness. A premise is an assumption that something is true or is believed to be true. It is a statement that an argument claim will induce or justify a conclusion (Audi, 1999: 43). The premises built and proposed then function to limit areas of data verification, knowledge advancement, and theory development on informal English elaborated in this research.

The steps of thinking in this research are presenting, identifying, and categorizing the corpus data. A synthesis on the data through discussions verifies the proposed premises. After the synthesis is completed, the conclusion is drawn. This train of thoughts is in line with a coding analysis in qualitative researches, i.e. an analysis technique with three elaborated coding steps: open, axial, and selective (Strauss \& Corbin, 1990; Holloway, 1997; Bohm, 2004; Saladana, 2012). 


\subsection{Source of the Data}

The data of this research are taken from URLs or Websites (web-data) as sources of informal English, for its necessary accounts and probable examples to be discussed and verified. For the sake of ease of referencing, the web-data are numbered accordingly (i.e. Web-Data 1; Web-Data 2; Web-Data 3; etc.) so that the data verified and the sources referred to are open for further elaboration by other researchers.

\subsection{Function of the Premises}

The premises function to limit areas for verification on the data of informal English. These premises will expectedly induce synthesized discussions and justify points in the conclusion. Other ways of thinking in this research are presenting, interpreting, and categorizing of the data, and then synthesizing of the data into discussions is made to confirm the premises. The final way of thinking is summarizing of the confirmed premises as new theories to be proposed to the open ELT world for further practices and theories.

\subsection{Statement of the Premises}

As informality is part of camaraderie to instill or confirm solidarity between or among close people, we can make the main point here that the endtarget of informality is camaraderie for solidarity. This point has been developed from the notion of closeness politeness which refers to Goffman's positive face (1959), Brown and Levinson's positive politeness strategies (1987), Renkema's solidarity politeness (1993), and Jumanto's friendship or camaraderie (2014), and which advocates the theory of power and solidarity by Brown and Gilman (1968). Based on the findings of the research by Jumanto $(2014 a ; 2014 b$; and his proposition, 2017), politeness and camaraderie have their distinctive characteristics in the types of form and topics they employ and elaborate in
Indonesian language, i.e. that the distant Indonesian language with formal, indirect, non-literal utterances, and carefully elaborated with safe and common topics, and that the close Indonesian language with informal, direct, literal utterances, and freely elaborated with any topics, personal and private.

\section{RESULT AND DISCUSSION}

\subsection{The Premise 1 (P1)}

This P1 states that the language of informal English employs utterances which are notorious, casual, heteregeneous, inconsistent, irregular, unorganized, incomplete, shorter, cutdown, reversed-up, and speakerdependent. This P1 has many aspects of informal English to confirm, and, therefore, the premise needs to verify various data from the web-sites (webdata) obtained upon a thorough search in the Internet.

Web-data 1 shows that in the form aspect of verb, transition, emphasis word, letter expression, abbreviation, and slang, informal English is shorter than the formal one, e.g.

$\begin{array}{ll}\text { sorry } & >\text { apologize } \\ \text { so } & >\text { therefore } \\ \text { really } & >\text { definitely } \\ \text { love } & >\text { yours sincerely } \\ \text { ASAP } & >\text { as soon as possible } \\ \text { kids } & >\text { children }\end{array}$

The notorious aspect is confirmed on the data that slang words belong to informal English, e.g.

$\begin{array}{ll}\text { kids } & >\text { children } \\ \text { bad } & >\text { negative } \\ \text { good } & >\text { positive }\end{array}$

The cut-down aspect reflects on the examples as follows:

$\begin{array}{ll}\text { photo } & >\text { photograph } \\ \text { cell } & >\text { cell phone } \\ \text { net } & >\text { internet }\end{array}$

And the inconsistent, irregular, and unorganized aspects, e.g. ASAP $>$ as soon as possible

${ }^{1}$ This sign $>$ from now on means instead of or for in this research paper. 


$\begin{array}{ll}\text { T.V } & >\text { television } \\ \text { photo } & >\text { photograph } \\ \text { cell } & >\text { cell phone } \\ \text { net } & >\text { internet }\end{array}$

These irregular examples are under no rules, and, therefore, is speakerdependent. The heteregeneous aspect emerges in the examples as follows:

$\begin{array}{lc}\text { say sorry } & >\text { apologize } \\ \text { go up } & >\text { increase } \\ \text { go down } & >\text { decrease } \\ \text { set up } & >\text { establish } \\ \text { look at } & >\text { examine }\end{array}$

Web-data 2 shows that informal English commonly has contractions, relative clauses without a relative pronoun and ellipsis, e.g.

$\begin{array}{ll}\text { she's } & >\text { she has } \\ \text { the girl I met } & >\text { the girl whom I met }\end{array}$

These contractions and ellipsis show the incomplete, shorter, cut-down, and speaker-dependent aspects of informal English. Web-data 2 also shows that more informal vocabulary commonly involves shorter words, or words with origins in Anglo-Saxon instead of those with origins in Latin and Greek, e.g.

$\begin{array}{ll}\text { start } & >\text { commence } \\ \text { end } & >\text { terminate } \\ \text { try } & >\text { endeavor }\end{array}$

This state of origins and the examples confirm the speaker-dependent and shorter aspects of informal English.

Web-data 3 shows that informal sentences are simpler and shorter, e.g.

looks like... > it looks like...

The data also shows that informal English is improvised and sloppy. Delaying, correcting, and qualifying expressions happen, e.g.

Well, I think they should have asked us first, you know?

He's not well. I mean, he's not sick, but he's very tired.

This whole blogging thing is getting kind of old.

Delaying expressions is to give one's self time, correcting expressions is to correct one's self, qualifying expressions is to show that what one said is not exactly right. The data also shows that informal English contains everyday phrases, e.g.

Here you are. There you go.

Excuse me? Come again?

What do you mean?

So, you're saying that...?

See you. Take care.

The data shows that informal English also involves slang words or phrases, e.g.

dude

freaking

nope

to puke

trashy

grownup

awesome

to chill out

And words or phrases in a shortened and simplified way, e.g.

Lemme go!

I'm doin' fine, whassup?

Whatcha gonna do?

In the data, simpler and shorter sentences confirm the incomplete and shorter aspects of informal English, while improvised and sloppy delaying, correcting, and qualifying expressions show the casual and speaker-dependent aspects. The everyday phrases including slang words and shortened and simplified expressions confirm the casual, speakerdependent, notorious, and shorter aspects of informal English. The state of conversational, improvised, simplified expressions, as summed up in this webdata 3 confirms the casual, speakerdependent, and shorter aspects of informal English.

Web-data 4 shows that Informal language includes taboo vocabulary, often labelled as vulgar slang in dictionaries or thesauruses. Vulgar slang refers to sex or bodily functions and generally should be avoided, as people find such terms offensive or shocking. The data shows examples of informal English, e.g.

\begin{tabular}{ll} 
fit & \multicolumn{1}{c}{$>$ attractive } \\
gear & $>$ clothes \\
crook & $>$ criminal \\
lay into & $>$ criticize
\end{tabular}




$$
\begin{array}{ll}
\text { gaff } & >\text { home } \\
\text { booze } & >\text { alcohol }
\end{array}
$$

The examples shown in the data confirm shorter, notorious, heteregeneous aspects of informal English.

Web-data 5 shows that it is not a problem for us to break the rules when using informal English, for instance when we are with friends or people our age in an informal location (like a restaurant or a party). The data shows 10 rules of formal English ready to break when we are using informal English, i.e. (1) Never end a

(1) Who should I study English with? $>$ With whom should I study

English?

(2) I have to go home. But Baby, it's cold outside. > I have to go home, but it's cold outside.

(3) ...to boldly go...

$$
>\text {...to go boldly... }
$$

(4) I've never met that person, but they seem nice. $>$ I've never met those people, but they seem nice.

(5) I would never $>$ I would never do that.

The data shows that the 10 expressions have broken the formal or correct English. This phenomenon shows and confirms the reversed-up, incomplete, casual, speaker-dependent aspects of informal English. The data sums up that the more we learn about which grammar rules can be broken, the more we will learn how to sound casual and natural using informal English.

Web-data 6 shows that informal English is used in more relaxed everyday situations. If we were telling a story to a friend, we would be more relaxed about our grammar. We might use short or broken sentences, everyday phrases or slang, and plenty of delaying, qualifying or correcting expressions. This data even without examples confirms the casual, shorter, and cut-down aspects of informal English.

Web-data 7 shows 10 informal English expressions, as follows:

Stay in touch. sentence with a preposition; (2) Never begin a sentence with a conjunction; (3) Never split infinitives; (4) Avoid the singular "they"; (5) Avoid sentence fragments and run-on sentences; (6) Avoid double negatives; (7) Treat collective nouns like they are singular; (8) The "less vs. fewer" rule; (9) The "that vs. which" rule; (10) The "I have vs. I've got" rule. The data shows examples of expressions as results of using informal English as follows:

(6) I don't have no work today. $>$ I don't have any work today.

(7) None of my friends are here.

$>$ None of my friends is here.

(8) ...less cats, less space... $>$...fewer cats, less space...

(9) The cat, that looks like a cat, lives here. $>$ The cat, which looks like a cat,

lives here.

(10) I've got to go now.

$>$ I have to go now

Jump to conclusions.

Sleep on it.

What a small world.

Never mind.

Come on.

It slipped my mind.

I owe you one.

Hang in there.

It's up to you.

The data shows the meaning of the expressions but does not explain why the expressions are all of informal English; however, in the light of the Premise 1 here in this section, the expressions confirm the incomplete, casual, and speakerdependent aspects of informal English.

Web-data 8 shows that informal English, cliches, and slang are different from standard or formal English. Informal English includes conversational English which involves contractions, e.g.

can't

won't

I'm

Cliches are words and phrases that tend to be overused and do not make for 
good writing and should be avoided in professional and academic writing, e.g.

Raining like cats and dogs.

Like a pig in mud.

Over the hill.

Meanwhile, slang is the use of words that are also not considered standard English, which should never be used in academic or professional writing. Slang words are developed from fads or simple laziness. The data shows examples of internet and texting slang, e.g.

$\begin{array}{ll}\text { D/L } & >\text { download } \\ \text { OMG! } & >\text { Oh my God! } \\ \text { LoL } & >\text { Laugh out loud } \\ \text { dat } & >\text { that } \\ \text { M2 } & >\text { me too } \\ \text { M9 } & >\text { mine }\end{array}$

Thus, as opposed to standard or formal English, cliches and slang may belong to informal English. The examples shown above in this data confirm the shorter, cut-down, notorious, spreakerdependent aspects of informal English.

Web-data 9 shows that informal English is more casual and spontaneous, is used when communicating with friends or family either in writing or in conversation, and is used when writing personal emails, text messages and in some business correspondence. Informal English employs contractions, phrasal verbs, slang/colloquialisms, first person pronouns, acronyms, and initialisms, e.g.

$\begin{array}{ll}\text { can't } & >\text { cannot } \\ \text { blown up } & >\text { inflated } \\ \text { the mob } & >\text { the crowd }\end{array}$

I considered the method.> The method was considered.

TAFE $>$ Technical and Further Education Sydney

UTS $>$ University of Technology

This account along with its examples confirms the casual, shorter, heteregeneous, notorious, and speakerdependent aspects of informal English.

Web-data 10 shows that informal English uses a very relaxed tone, contractions, idioms, slang, and phrasal verbs. It is more commonly used when we are speaking at a party or in social media. The data gives examples of informal English, e.g.

They'll attend the meeting tomorrow. > They will attend the meeting tomorrow.

Sorry. > I would like to apologise for any inconvenience caused.

I wanna pass my English exam tomorrow. > I want to pass my English exam tomorrow.

The data confirms the casual, shorter, incomplete, notorious, speakerdependent, heteregeneous aspects of informal English.

Web-data 11 shows three informal ways to ask people to wait for a very short time, i.e.

A minute, a second, a sec, one sec. > One moment, please.

Informal expressions like these make our English sound more relaxed and conversational. This account and examples in the data confirms casual and shorter aspects of informal English.

Web-data 12 shows the use of informal English greetings with people we are close to, including friends, family members, classmates, and coworkers, e.g.

Hey! What's up? > Hello, how are you?

The data explains that the word HEY in informal English is not for horses but is a very common informal greeting to use with friends and people we know very well, especially in most informal situations, e.g.

Hey, what's up?

Hey, how are you?

Hey, you!

Hey, boy.

Hey, girl.

Hey, can we talk?

Hey, there.

The data also shows that one of the signs of informal English is the habit of leaving out words in phrases to make the language seem more casual, for example, to our sibling, e.g.

Morning.

Good morning.

How ya doing? > How are you doing?

This account along with examples in the data shows that informal English has 
casual, shorter, incomplete, heteregeneous, and speaker-dependent aspects.

Web-data 13 explains about informal English and slang differently. It shows that most sources agree that informal English typica lly avoids long, complex sentences, features a liberal use of contractions and other casual terms, allows elided pronunciations like: gonna > going to

Informal English tends to be short, metaphorical, and somewhat out of place in carefully edited, serious prose. Informal English includes terms like:

abs
carb
guys
big shot
Spill the beans.
Knock it off.

A wide range of users in relaxed circumstances, including educated speakers, choose informal English, as it is familiar, intimate, and unpretentious. The account and examples in this data confirm the casual, shorter, heteregeneous, speaker-dependent aspects of informal English.

\subsection{The Premise $2(\mathrm{P} 2)$}

This P2 states that the language of informal English is direct. The word direct means honest; free in expressing one's true feelings and opinions (Cambridge, 2020; Merriam-Webster, 2020), or frank; going straight to the point (Oxford, 2020).

These accounts are in line with what has been long stipulated by Arndt and Janney that the utterance in which the speaker associates himself and his listener very closely with the requested act, was viewed as more direct or commanding than the other utterances (1987: 177). Thus, informal English is direct, as it is honest, frank, and free in expressing the speaker's or the writer's true feelings and opinions or going straight to the point. The honest, frank, and free expressions as the direct nature of informal English are confirmed by the casual, shorter, cutdown, speaker-dependent, and notorious aspects of the informal English.

4.3. The Premise 3 (P3)

This P3 states that the language of informal English is usually literal. The word literal means the original, basic meaning of a word (Cambridge, 2020); restricted to or based on fact (Merriam-Webster, 2020), and taking words in their usual or most basic sense without metaphor or exaggeration (Oxford, 2020).

Thus, the literal nature of informal English refers to the original, basic meaning of words based on fact and in their usual sense, including everyday phrases shown in the examples above, i.e.

bad, good
start, try
Come again? What do What 2$)$
(Web-Data 3)
This literal nature of informal
English is then in line with the notorious and casual aspects of the informal English.

4.4. The Premise 4 (P4)

This P4 states that the language of informal English employs any topics, personal and private. The word personal means relating or belonging to a single or particular person rather than to a group or an organization (Cambridge, 2020); of, relating to, or belonging to a single person (Merriam-Webster, 2020); or belonging to or affecting a particular person rather than anyone else (Oxford, 2020). Meanwhile, the word private means only for one person or group and not for everyone (Cambridge, 2020); not known or meant to be known by the general populace (Merriam-Webster, 2020); belonging to or for the use of one particular person or group of people only (Oxford, 2020). Thus, a personal or private topic is an 
object, a matter, a subject, or a concern which belongs to a particular person or group of people only, not for everyone or the general populace.

Based on this premise, the web-data confirms that informal English may involve topics as follows:

(1) taboo vocabulary or vulgar slang referring to sex or bodily functions (Web-Data 4)

(2) stories to friends (Web-Data 6)

(3) emailing or texting to friends (WebData 8)

(4) writing or conversations to friends or family (Web-Data 9)

(5) greetings to close people (Web-Data 12)

(6) swearings for the social rapport (WebData 16)

As informal English is used in the context of a particular group of people with any topics, personal and private, this confirms the notorious, casual, heteregeneous, inconsistent, irregular, unorganized, speaker-dependent aspects of the informal English.

\subsection{The Premise 5 (P5)}

This P5 states that the language of informal English is spoken to close people. The term close people means those who know each other very well and like each other a lot or who see and talk to each other a lot (Cambridge, 2020); who are intimate or familiar (MerriamWebster, 2020); or who are very affectionate or intimate (Oxford, 2020).

Thus, the web-data within this premise confirms that:

(1) Informal English is spoken between or among those who are intimate, familiar or affectionate and know, like, and talk to each other or one another a lot. Informal English is used with friends, children, and relatives. (Web-Data 1)

(2) Informal English is used when writing postcards or letters to friends, emails or text messages.

(Web-Data 2)

(3) Informal English is used for everyday conversations and in personal letters, in an Internet chatroom or in quick, personal emails. (Web-Data 3)

(4) Informal English is mainly used between people who know each other well, or in relaxed and unofficial contexts. (WebData 4)

(5) Informal English is used with friends or people our age in an informal location (like a restaurant or a party). (Web-Data 5)

(6) Informal English is used with people we are close to, including friends, family members, classmates, and coworkers. (Web-Data 12)

\subsection{The Premise 6 (P6)}

This P6 states that the language of informal English functions to instill or confirm solidarity. Solidarity is agreement between and support for the members of a group (Cambridge, 2020); unity (as of a group or class) that produces or is based on community of interests, objectives, and standards (Merriam-Webster, 2020); or unity or agreement of feeling or action, especially among individuals with a common interest; mutual support within a group (Oxford, 2020). Thus, solidarity refers to agreement, support, and unity of feeling and action among people with common interests.

From the web-data, it is found out that informal English (including slang) confirms things as follows:

(1) it encourages intimacy, solidarity and a social connection with the audience/speakers to build social rapport. (Web-Data 16)

(2) it is the glue that binds society, creating rapport and friendliness.(Web-Data 17)

(3) its is a marker of in-group solidarity and a correlate of human groups with shared experiences. (Web-Data 18)

(4) it indicates membership of a social group to strengthen solidarity and diverge from others.(Web-Data19)

\section{CONCLUSION}

Based on the proposed premises, the results and discussions on the accounts given and web-data verification, some points to bring this paper to an end are given below.

The aspects of informality in the English language have been identified through this simple research on informal 
English. Based on the results of this research, informal English involves the notorious, casual, heteregeneous, inconsistent, irregular, unorganized, incomplete, shorter, cut-down, reversedup, and speaker-dependent aspects upon data verification on web-data of informal English utterances or expressions. Informal English also shows the direct nature of its utterances or expressions, as it is honest, frank, and free in expressing the speaker's or the writer's true feelings and opinions straight to the point. Informal English also has the literal nature, as it refers to the original, basic meaning of words based on fact and in their usual sense, including phrases in everyday or daily conversations.

Informal English employes any topics, personal and private. Personal and private topics belong to a particular person or group of people only, not for everyone or the general populace, e.g. taboo vocabulary or vulgar slang of sex or bodily functions, stories to friends, emailing or texting to friends, writing or conversations to friends or family, greetings to close people, and swearings for the social rapport.

Informal English is used between or among close people. Close people are intimate, familiar, or affectionate, and are those who know, like, and talk to each other or one another a lot. Informal English is used with friends, children, relatives, family friends, classmates, people of the same age, and coworkers, in everyday conversations, in personal letters or emails, in an internet chatroom or an informal location like a restaurant or a party, or in relaxed and unofficial contexts.

Informal English which shares the informal aspects, the direct and literal nature, with any topics, personal and private, between or among close people, functions to confirm solidarity between or among them. Solidarity refers to agreement, support, and unity of feeling and action among people with common interests. Solidarity reflects intimacy, a social connection with the audience/speakers to build social rapport and friendliness, and membership of a social group.

As informal English is important for confirming solidarity with close people, English Language Teaching (ELT) should consider its involvement in classrooms' teaching and learning process. Knowledge and practices of informal English are necessary for teachers as well as learners. ELT teachers should include informal English in their teaching-syllabus material with particularly-set circumstances, i.e. with close people and within informal situations. Types of close people (i.e. hearer) should be well-elaborated under the theory of power and solidarity (Brown and Gilman, 1968), while informal situations should also be identified to differ from formal situations.

From the learners' side, informal English should also be mastered and applied in their daily interactions or communication, besides their mastery of formal or standard English. Learning the knowledge and practices of informal English through classrooms' teaching and learning process should prevent English learners from uncontrolled learning exposures to various informal morallydangerous settings, e.g. in the Internet, at public places, overheard adult talks, videos, televisions, and movies. Knowledge and practices of informal English and its involvement in ELT classrooms will expectedly encourage English learners to be alert and careful in using informal English, hence encouraging them to maintain interpersonal and social harmony to some broader extent.

All these findings and recommendations are in line with the concerns on developing ELT theories and 
practices in the world, e.g. on intercultural communicative competence and due pragmatic emphasis on teacher training courses (Tan and Farashaiyan, 2016: 45), on validation of CAF-measurement of the written performance quality (Dahmardeh and Shahmirzadi, 2016: 639), on reflection of language proficiency and ELT in Malaysia (Lian, 2016: 59).

\section{ACKNOWLEDGEMENT}

We would like to extend our gratitudes to all the authors of the socalled Web-Data 1 through 19 within this research, for all their precious opinions as well as vivid data of informal English.

\section{REFERENCES}

Arndt, H., \& Janney, R. W. (1987). InterGrammar: Toward an Integrative Model of Verbal, Prosodic, and Kinesic Choices in Speech. Berlin: Walter de Gruyter \& Co.

Audi, Robert, ed. (1999). The Cambridge Dictionary of Philosophy (2nd ed.). Cambridge: Cambridge University Press.

Baker, M. J. (2000). Writing a Literature Review. The Marketing Review, 1(2), 219-247.

https://doi.org/10.1362/146934700 2529189.

Bangasser, P. E. (2000). The ILO and the Informal Sector: An Institutional History. Geneva: International Labour Office.

Bohm, A. (2004). "Theoretical coding: text analysis in grounded theory", in U. Flick, E. Kardorff \& I. Steinke (Eds.), A Companion to Qualitative Research. London: SAGE Publications, pp. 270-275.

Bolderston, A. (2008). Writing an Effective Literature Review. Journal of Medical Imaging and Radiation Sciences, 39, 86-92. https://doi.org/10.1016/j.jmir.20 08.04.009.

Brown, P., \& Levinson, S. C. (1987). Politeness: Some Universals in Language Usage. New York: Cambridge University Press.

Brown, R., \& Gilman, A. (1968). The Pronouns of Power and Solidarity. In J. A. Fishman (Ed.), Readings in the Sociology of Language (pp. 252-275). The Hague: Mouton \& Co. N.V. Publishers.

Cambridge. (2020). Cambridge Dictionary,

https://dictionary.cambridge.org/dict ionary/english/direct

Dahmardeh, M. and Shahmirzadi, N. (2016). Measuring the Written Performance Quality in terms of (CAF) Complexity, Accuracy and Fluency Constructs, Pertanika Journal of Social Sciences \& Humanities, 24(2): 639-654 (2016).

Goffman, E. (1959). The Presentation of Self in Everyday Life. New York: Anchor Books.

Heintz, James. (2012). 'Informality, Inclusiveness, and Economic Growth: An Overview of Key Issues', SIG WORKING PAPER 2012/2. Amherst, USA: Political Economy Research Institute, University of Massachusetts, July 2012.

Holloway, I. (1997). Basic concepts for qualitative research. Oxford: Blackwell Science Ltd.

Jumanto, J. (2014a). Politeness and Camaraderie: How Types of Form Matter in Indonesian Context. Proceeding: The Second International Conference on Education and Language (2nd ICEL). Bandar Lampung University (UBL), Indonesia.

Jumanto, J. (2014b). Towards a Character Language: A Probability in 
Language Use, Open Journal of Modern Linguistics (OJML), 2014(4): 333-349. http://dx.doi.org/10.4236/ojml.2 014.42027

Jumanto, J. (2017). Educating the Indonesian Language: A Proposed Verbal Social Project for the National Harmony. Advances in Social Sciences, Education and Humanities Research (ASSEHR)YICEMAP-17, Amsterdam: Atlantis Press (BV), ISBN 978-94-6252363-0 ISSN 2352-5398, Vol. 66, pp. 215-221. doi:10.2991/yicemap17.2017.36.

Jumanto, J., Rizal, S.S., \& Nugroho, R.A. (2017). Acting the Intangible: Hints of Politeness in Non-Verbal Form, English Language Teaching, 10 (11), 2017, 111-118.

Kanbur, Ravi. (2009). 'Conceptualising Informality: Regulation and Enforcement', at www.people. Cornell.edu/pages/sk145, February, 2009.

Lian, K.L. (2016). Malaysian English or Grammatical Errors? Pertanika Journal of Social Sciences \& Humanities, 24(S): 59-72 (2016).

Merriam-Webster. (2020). MerriamWebster, Since 1928, https://www.merriamwebster.com/thesaurus

Oxford. (2020). English, Oxford Living Dictionary,

https://en.oxforddictionaries.com/de finition

Renkema, J. (1993). Discourse Studies: An Introductory Textbook. Amsterdam: John Benjamins Publishing Company.

Saladana, J. (2012). "The coding manual for qualitative researchers", Sage, ISBN 1446247376. London: SAGE Publications.

Sifianou, Maria. (2013). The Impact of Globalisation on Politeness and
Impoliteness, Journal of Pragmatics 55 (2013) 86-102.

Sindzingre, Alice. (2006). 'The Relevance of the Concepts of Formality and Informality: A Theoretical Appraisal' in Linking the Formal and Informal Economy: Concepts and Policies, Basudeb GuhaKhasnobies, Ravi Kanbur, and Elinor Ostrom eds. Oxford: Oxford University Press, UNU-WIDER Studies in Development Economics and EGDI.

Strauss, A. \& Corbin, J. (1990). Basics of qualitative research: grounded theory procedures and techniques. California: Sage Publications.

Tan, K. H. And Farashaiyan, A. (2016). Challenges in Teaching Interlanguage Pragmatics at Private EFL Institutes in Iran, Pertanika Journal of Social Sciences \& Humanities, 24(S): 45-54 (2016).

Webster, J., \& Watson, R. T. (2002). Analyzing the past to prepare for the future: writing a literature review. MIS Quarterly, 26(2), xiii-xxiii. 
